\title{
Design and experimental study of the four-drum net winch
}

\author{
LIN Liqun ${ }^{1, \mathrm{a}}$, CHEN Zhixin ${ }^{1, \mathrm{~b}}$, XU Zhiqiang ${ }^{1, \mathrm{c}}$, WANG Zhiyong ${ }^{1, \mathrm{~d}}$ \\ ${ }^{1}$ Fishery Machinery and Instrument Research Institute, Chinese Academy of Fishery Science, \\ Shanghai, China \\ a linliqun@fmiri.ac.cn, ${ }^{\mathrm{b}}$ chenzhixin@fmiri.ac.cn, ${ }^{\mathrm{c}}$ xuzhiqiang@fmiri.ac.cn, \\ d wangzhiyong@fmiri.ac.cn
}

Keywords: Ocean going seiners. Net winch. Friction belt drive principle. Hauling tension. Wrap angle

\begin{abstract}
Net winch is a major fishing net equipment for retracting and pulling fishing nets. Currently, the multi-drum net winch is widely used in the ocean going seiners. It is mainly based on the tensile load and velocity to design the net winch drum drive device and drum numbers. The structure includes a main frame, drive drums, reduction gear box, gears, hydraulic motor, the base etc. In order to meet the demand of "Le ting" seiner, which is fishing in Mauritania and other West African waters, the four-drum net winch was designed based on the friction belt drive principle, a multi-drum drive model and three-dimensional simulation model of four-drum net winch was constructed, and prototype model was manufactured. Through the load test, the results show that tension of the net exit measured by the test is approximately equal to that of the theoretical calculation, and meet the design requirements. This design of four-drum net winch in this paper provides an important reference for designing the same type of seine net winch.
\end{abstract}

\section{Introduction}

Net winch is a main fishing equipment of the fishing vessels, its main function is to retract and pull fishing nets and catches. With the development of the world's oceans offshore fishing, net winch has been widely used in the fishing around the world [1] [2], it is the indispensable key equipment in the production of fishing vessels.

At present, the length of large nets is usually $800-1000 \mathrm{~m}$ or up to $1500 \mathrm{~m}$, some large tuna purse-seine nets even up to $2500 \mathrm{~m}$, the nets weight can reach $15 \sim 20 \mathrm{t}$. It is too difficult to rise these nets, if only relying on manual strength. Thus, it is necessary to use the specialized fishing equipment [3] [4]. However, China's existing net winches are aging, low level of automation, low performance, which do not match the new fishing vessels. In addition, modern fishing production has changed the work way of the net winch, which result in limited development [5]. When some current domestic offshore fishing companies and shipyards equip with the net winch equipment, especially for some high-power ones, most of them rely on imports, which seriously restricted the development of offshore fishing. Therefore, in order to meet the development of China's demand for ocean-going fishing vessels fishing advanced equipment and technology, it is of significance to study the nets winches.

\section{Principle of the Multi-drum net winch}

Net winch is in accordance with the principle of transmission to transmit the drive force by friction between the contact surfaces of the drive drum and nets. The winch drum surface is covered with a 
layer of rubber, the nets attach to the rubber drums when hauling, with the drum rotating, the nets are directly received from the sea on board fishing vessels under manual auxiliary tension [6]. According to Euler's formula, the relation of the tension, the wrap angle, and the friction coefficient is expressed as [7]:

$$
F_{1}=F_{1}^{\prime} \mathrm{e}^{\mu \alpha}
$$

Where $F_{1}$ is the tight side tension of meeting point between the drum and nets, unit $\mathrm{kN}$; $F_{1}$ 'represents the loose side tension of separation point between the nets and drum., unit $\mathrm{kN}$; e is natural logarithms, $\mu$ is the friction coefficient between the drum and nets ; $\alpha$ denotes the nets covering drums angle, referred to as wrap angle, unit rad.

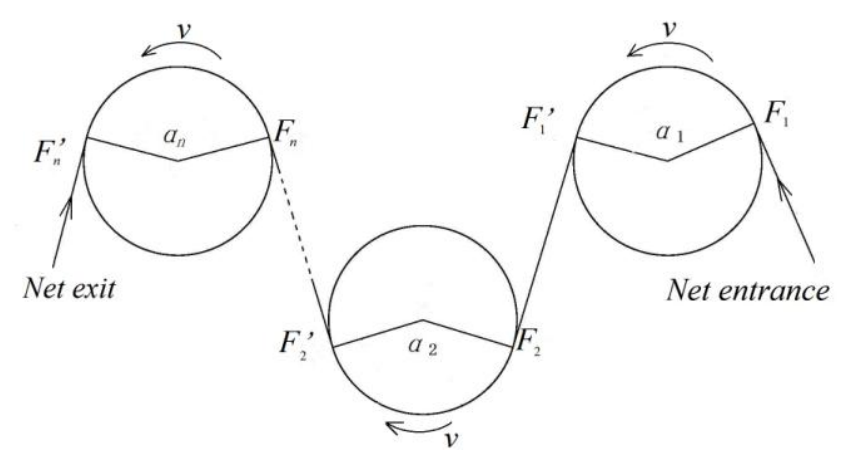

Fig. 1 Drive model of the multi-drum net winch

From the formula (1), it can be seen that when hauling tension is large, increasing the friction coefficient $\mu$ and the wrap angle $\alpha$ can make manual tension smaller. Under the condition of constant friction coefficient $\mu$, increasing the wrap angle $\alpha$ can increase the tensile load, and by increasing the number of drums can significantly increase the wrap angle. Thus, multi-drum net winch is using the belt friction drive principle to achieve greater hauling tension load and reduce the net end manual tension, by increasing the number of drive drum to increase wrap angle to meet the requirements of the hauling tensile load, two or more drums net winch is proposed. Drive model of multi-drum machine net winch is shown in Figure 1, assuming the net winch is composed of $n$ drums ( $\mathrm{n}$ is the integer greater than or equal to 2 ), the tension between the two ends of one drum can be expressed as:

$$
F_{n}=F_{n} \mathrm{e}^{\mu \alpha_{n}}
$$

Where $F_{n}$ is the tight side tension of meeting point between the n-th drum and nets; $F_{\mathrm{n}}$ ' represents the loose side tension of separation point between the $n$-th drum and nets; $\alpha_{n}$ denotes the nets covering the $\mathrm{n}$-th drum angle. Where, the slack side tension of the $\mathrm{n}$-1-th drum separating point is equal to the tight side tension of the $\mathrm{n}$-th drum meeting point, that is:

$$
F_{n-1}{ }^{\prime}=F_{n}
$$

The theoretical output torque $\mathrm{T}$ is:

$$
T=\left(F_{1}-F_{n}^{\prime}\right) \cdot(D+d) / 2
$$

Due to the sliding friction factor and the effective use of the wrap angle, the actual output torque $T_{\mathrm{s}}$ is greater than the theoretical output torque $T$, the actual torque can be got as:

$$
T_{s}=T / \zeta
$$


Where, $\zeta$ is the effective utilization coefficient. Adopting multi drums can effectively increase the wrap angle and reduce the material strength of the nets and the drums, and reduce the capacity of each drive unit, the total net winch wrap angle $\alpha$ is:

$$
\alpha=\alpha_{1}+\alpha_{2}+\ldots+\alpha_{n}
$$

Put the formula (2) and the formula (3) into the formula (6), to simplify:

$$
\alpha=\frac{1}{\mu} \ln \left(\frac{F_{1}}{F_{1}^{\prime}}\right)+\frac{1}{\mu} \ln \left(\frac{F_{2}}{F_{2}^{\prime}}\right)+\ldots+\frac{1}{\mu} \ln \left(\frac{F_{n}}{F_{n}^{\prime}}\right)=\frac{1}{\mu} \ln \left(\frac{F_{1}}{F_{n}^{\prime}}\right)
$$

Let each drive drum wrap angle are equal, formula (7) is provided:

$$
\alpha_{n}=\frac{1}{\mu n} \ln \left(\frac{F_{1}}{F_{n}^{\prime}}\right)
$$

To reduce human labor, when the hauling load is greater than a certain value, it generally needs to be equipped the net winch on the fishing vessels, which saves labor force at the net exit, when $T_{\mathrm{n}}{ }^{\prime} \leq 200 \mathrm{~N}$. The friction factor is general 0.5 , according to the main parameters of net winch tension in practical application, a single drive drum wrap angle ranges from $\pi / 2$ to $4 \pi / 3 \mathrm{rad}$, the wrap angle of the first drum on net entrance ranges from $\pi / 2$ to $\pi \mathrm{rad}$, the inequality is obtained by the formula (8):

$$
\left\{\begin{array}{l}
\frac{\pi}{2} \leq \frac{1}{\mu n} \ln \left(\frac{F_{1}}{F_{n}^{\prime}}\right) \leq \pi,(n=1) \\
\frac{\pi}{2} \leq \frac{1}{\mu n} \ln \left(\frac{F_{1}}{F_{n}^{\prime}}\right) \leq \frac{4 \pi}{3},(n \geq 2)
\end{array}\right.
$$

After discussion and calculation, the results are showed in Table 1

Tab.1 Relations of the net hauling tension, the wrap angle and the drum quantities

\begin{tabular}{ccc}
\hline Total wrap angle $\alpha$ & Drum numbers $n$ & Hauling tension $F_{1}$ \\
\cline { 3 - 3 }$/ \mathrm{rad}$ & & $/ \mathrm{kN}$ \\
\hline$\left[\frac{\pi}{2}, \pi\right]$ & 1 & {$[0.4,1.0]$} \\
{$\left[\pi, \frac{7 \pi}{3}\right]$} & 2 & {$[1.0,7.8]$} \\
{$\left[\frac{3 \pi}{2}, \frac{11 \pi}{3}\right]$} & 3 & {$[2.1,63.4]$} \\
{$[2 \pi, 5 \pi]$} & 4 & {$[4.6,515.2]$} \\
\hline
\end{tabular}

\section{Structural Design}

The net winch is designed for a distant-water seiner named "Leting". This distant-water seiner is mainly used for seine fishing in Mauritania, West Africa in Seine area near Greater Coastal Service, which length is $26.8 \mathrm{~m}$, width is $8.2 \mathrm{~m}$. The net winch related parameters are designed as follows, the rated hauling tension $F_{1}=40 \mathrm{kN}$, maximum hauling tension is $50 \mathrm{kN}$, and maximum hauling velocity is $v=45 \mathrm{~m} / \mathrm{min}$. 
According to the design requirements, the output power of the net winch is at least $30 \mathrm{~kW}$. High-pressure hydraulic drive method is used at the net winch drive system. The hydraulic motor drives the reduction gear box to make the drum rotate at rated velocity. As the calculated results shown in Tab 1 , the hauling tension is $40 \mathrm{kN}$, which means a three-drum or four-drum net winch can meet criteria of the rate hauling tension greater than $40 \mathrm{kN}$. However, according to the purse-seine fishing way and structure, a seine transport-roller is installed high above the exit of the net winch. When using the three-drum net winch, the net at outlet end would turn upwards $90{ }^{\circ}$ and rise to the seine transport-roller, in this case, wrap angle is hardly formed at the exit of the net winch, in fact, only two drums have effect, so as not to meet the requirements of tension. Accordingly, four-drum structure is applied to the net winch to maintain a larger wrap angle and effectively using the advantages of drum, the four drums is arranged as the following Figure 2:

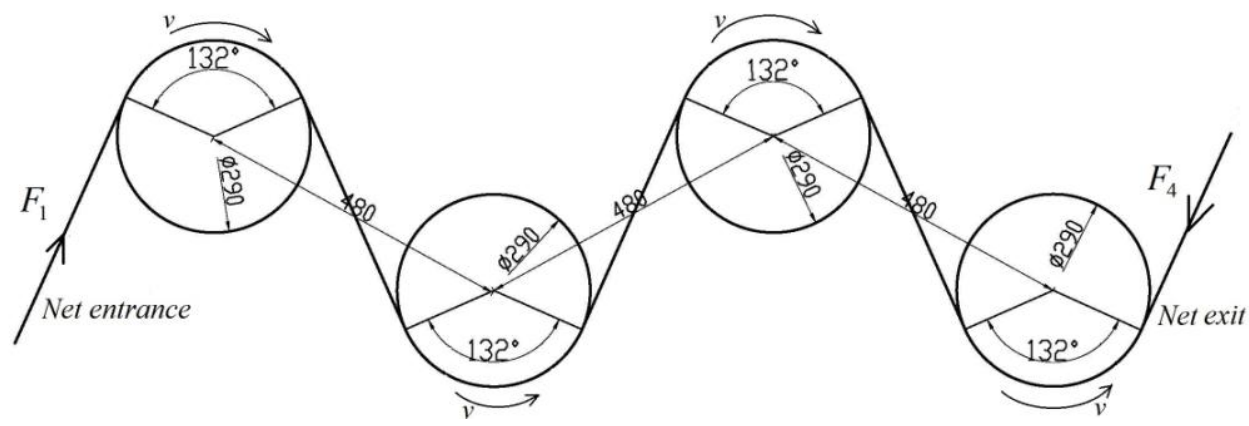

Fig.2 Schematic of four drums arrangement

Assuming that the friction coefficient $\mu$ is set to 0.5 , and effective utilization coefficient $\zeta$ is 0.85 , the tension of the net exit $F_{4}$ can be got by the formula (2) and (3), and the actual output torque $T_{\mathrm{s}}$ can be got from the formula (4) and (5) :

$$
\begin{aligned}
& F_{4}=F_{1} / e^{\mu\left(\alpha_{1}+\alpha_{2}+\alpha_{3}+\alpha_{4}\right)}=40 / e^{0.5 \times\left(\frac{132}{180} \times 3.14 \times 4\right)}=0.4 k N \\
& T_{s}=\left(F_{1}-F_{4}\right) \cdot(D+d) / 2 \varsigma=(40-0.4) \times 10^{3} \times(290+20) \times 10^{-3} /(2 \times 0.85)=7221 \mathrm{~N} \cdot \mathrm{m}
\end{aligned}
$$

Where, $D$ is the drum diameter, $\mathrm{mm} ; d$ is the net thickness, $\mathrm{mm}$. The hydraulic motor displacement $q_{\mathrm{m}}$ is $900 \mathrm{ml} / \mathrm{r}$, the rotational speed $n_{\mathrm{m}}$, the torque $T_{\mathrm{m}}$, the system flow rate $Q_{\mathrm{m}}$ and the working pressure of hydraulic motor $P_{m}$ are respectively:

$$
\begin{aligned}
& n_{m}=\frac{v \cdot i}{\pi(D+d)}=\frac{45 \times 3.8}{3.14 \times(290+20) \times 10^{-3}}=175 \mathrm{r} / \mathrm{min} \\
& Q_{m}=\frac{q_{m} \cdot n_{m}}{\eta_{\mathrm{vm}}}=\frac{900 \times 175}{0.92}=171 \mathrm{~L} / \mathrm{min} \\
& T_{m}=\frac{T_{s}}{i \cdot \eta_{c}}=\frac{7221}{3.8 \times 0.95}=2000 \mathrm{~N} . \mathrm{m} \\
& P_{m}=\frac{2 \pi T_{m}}{q_{m} \times \eta_{m m} \times \eta_{v m}}=\frac{2 \times 3.14 \times 2000}{900 \times 0.91 \times 0.92}=16.7 \mathrm{MPa}
\end{aligned}
$$

Where, $\eta_{v m}, \eta_{m m}$ respectively represent mechanical efficiency and volumetric efficiency of hydraulic motor, their values are 0.91 and $0.92 . \quad \eta_{c}$ is gear efficiency which value is 0.95 . The transmission 
ratio $i=3.8$.

The net winch system consists of two main parts, mechanical and hydraulic components, of which machinery structure is shown in Figure 3, it mainly consists of a frame, four drums, a gear box, baffles and other components, all of these components are mounted on the frame that is installed on the deck of the seiner. As an important design parameters, the drum length is $600 \mathrm{~mm}$, diameter is $290 \mathrm{~mm}$, and the total wrap angle is $528^{\circ}$ (that is $9.2 \mathrm{rad}$ ). The hydraulic parts include hydraulic motor, control valves, hydraulic cylinders etc. Drum rotating is achieved by a motor-driven gear, velocity of the drum can be adjusted continuously from 0 to $45 \mathrm{~m} / \mathrm{min}$ by operating manual proportion reversing valve.
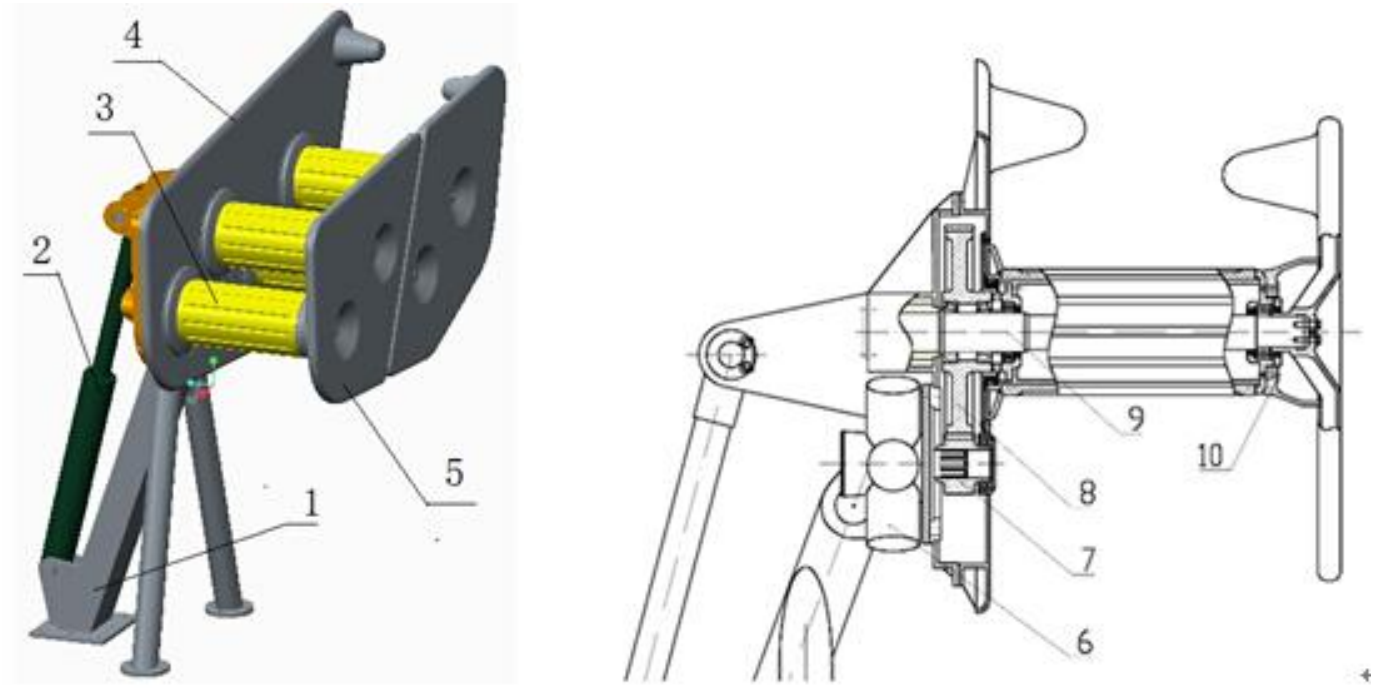

1 base, 2 variable amplitude cylinder, 3 roller, 4 reduction gear box, 5 guard board, 6 hydraulic motors, 7 pin ion, 8 big gear, 9 axis, 10 roller head,

Figure 3. Four-drum net winch structure

\section{Experimental Design}

The experiment is conducted in the Key Laboratory of Fishery Equipment and Engineering Ministry of Agriculture, the experimental arrangement is shown in Figure 4, it is driven by the hydraulic system. Three tons' hanger rig is used as tension loading equipment which height is $14 \mathrm{~m}$ and carrying capacity is greater than $300 \mathrm{kN}$. Through loading weights to simulate hauling tension. The measuring equipment consist of weights, stopwatch, pressure gauge that measures system operating pressure, and thermometer measuring oil temperature of this hydraulic system.

Attention should be paid to the experiment before, the net winch and hydraulic system is running smoothly, no unusual vibration, shock, noise and leakage, bearings and moving parts temperature are normal, start, reversing, and stopping must be responsive shifting.

Test includes no-load test and load test, experimental procedure is as follows:

1) Start pumping and run in five minutes, then start the net winch operating for 30 minutes in unloading condition before reverse running for three minutes.

2) Start the manual proportion reversing valve and adjust the speed for 5 to 10 times, and slowly pull the proportional reversing valve handle to make the drum forward rotation speed increase from zero. When the speed reaches the maximum value, push the valve handle, the drums speed gradually decelerate to stop, continue to push the valve handle until the drum reverse speed increases.

3) Several groups of tension from $20 \mathrm{kN}$ to $50 \mathrm{kN}$ is respectively loaded on the net winch, and do 
the load lifting test more than three times. Measure and record the hydraulic system pressure and tension of the net exit under various conditions, each test must be repeated three times or more.

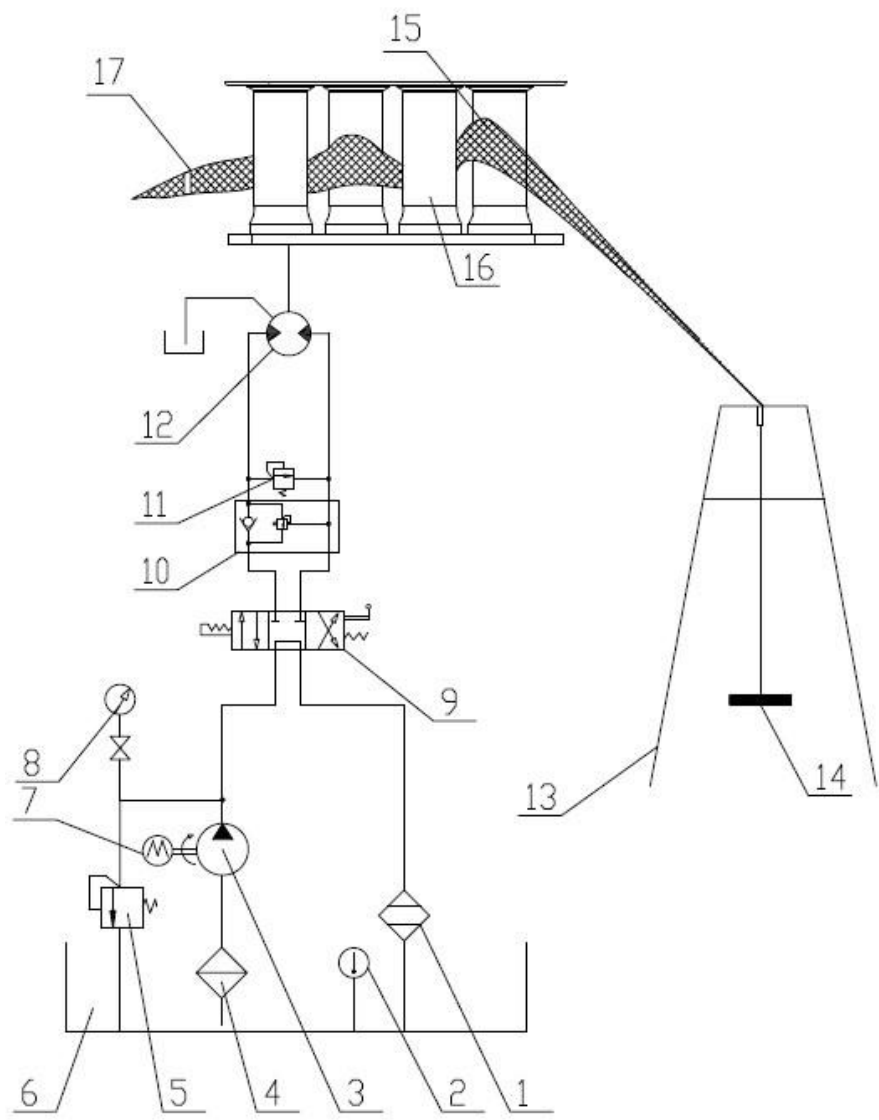

1 oil return filter, 2 thermo meter, 3 hydraulic ram pu mp, 4 oil suction filter, 5 relief valve, 6 oil tank, 7 motors, 8 gauge,

9 Manual proportion reversing valve, 10 balancing valve, 11 valves, 12 hydraulic motor, 13.3 tons hanger rig, 14 weights, 15 nylon fishing nets, 16 four-d rum net winch, 17 tension sensor.

Fig. 4 Test configuration of the net winch hydraulic system

\section{Results and analysis}

The unload test results is shown in Table 2, it shows that the net winch functions well, and do not produce these undesirable phenomena such as abnormal vibration or shock leakage, the maximum speed is $51 \mathrm{r} / \mathrm{min}$.

Tab.2 The no-load test results

\begin{tabular}{cccc}
\hline \multirow{2}{*}{ Conditions } & Maximum speed & System pressure & Running time \\
\cline { 2 - 4 } & $\mathrm{r} / \mathrm{min}$ & $\mathrm{MPa}$ & $\min$ \\
\hline Forward rotation speed & 51 & 0.1 & 30.0 \\
Reverse rotation speed & 51 & 0.1 & 30.0 \\
\hline
\end{tabular}

Figure 5 is a curve obtained under the load test condition, it shows that the tension of the net exit changes with the net winch hauling tension, the drum velocity is $v=30 \mathrm{~m} / \mathrm{min}$. Hauling tension is that is of the tension of the net entrance, relationship of hauling tension and tension of the net exit coincides with Formula (1). The tension measured by the test is approximately equal to that of the theoretical calculation, and increase with increasing hauling tension. 

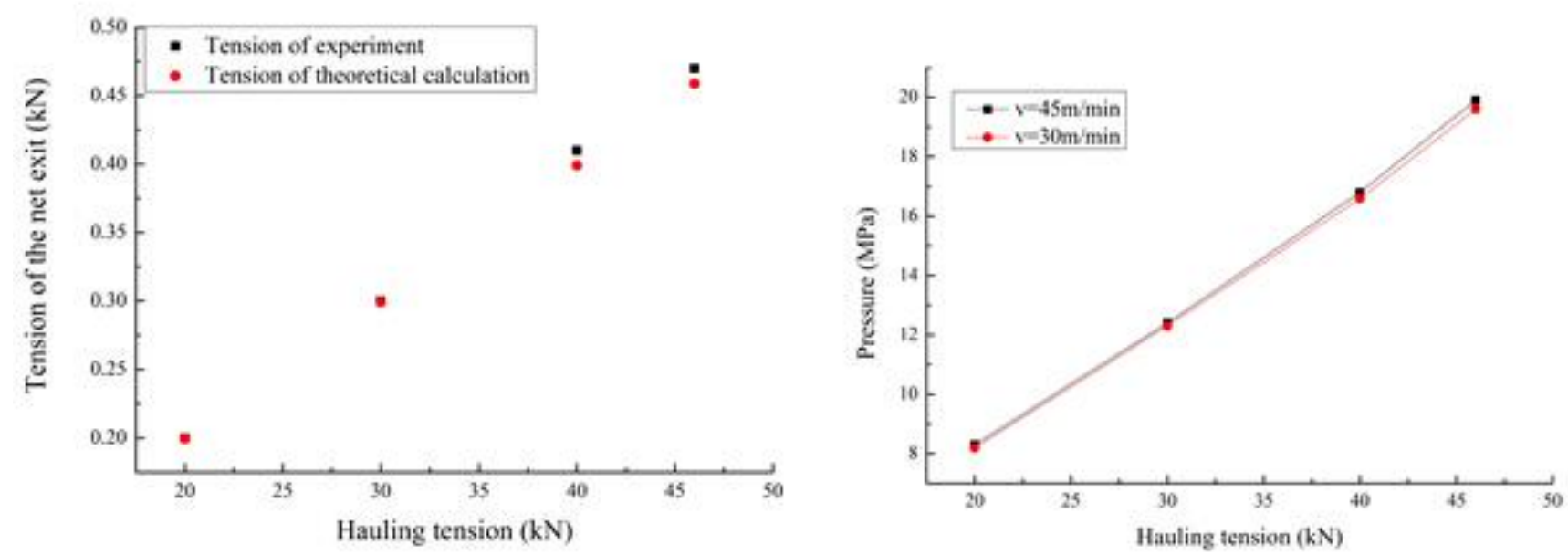

Fig.5 Tension changes with the hauling tension.

Fig.6 Curves of pressure changing with the hauling tension .

Figure 6 is a curve of pressure changing with the hauling tension, it shows that the pressure does not change when the drum velocity changes in the same hauling condition, and increase with increasing tension. The pressure measured by the test at $F_{1}=40 \mathrm{kN}$ is almost equal to that of the theoretical calculation, where the experimental pressure value is $16.5 \mathrm{MPa}$.

\section{Conclusion}

The four-drum net winch was designed by friction belt drive principle and experiment was conducted in this paper. Through the theoretical calculation and load test, the results show that the design of four-drum seine net winch meet the design requirements, the tension and pressure measured by the test is approximately equal to that of the theoretical calculation. This design net winch in this paper provides an important reference for designing the same type of seine net winch.

\section{Acknowledgements}

This work was financially supported by the Key Projects in the National Science \& Technology Pillar Program under Grant No. 2013BAD13B02

\section{References}

[1]. Chen Zhixin, Wang Zhiyong, Xu Zhiqiang. Advances in equipment of fishing vessels in China. In Proc. China Fishing Equipment Technology Development Forum, Nanjing, (2012), p.87-93.

[2]. He Bo: Status and development trend of the world fishing equipment and technology. In Proc. China Fishing Equipment Technology Development Forum, Nanjing, (2012), p.67-71.

[3]. Le Jiahau. Current situation and trend of the development of Japanese ocean fishery. J. World Agriculture. (2013), 5, p.37-40.

[4]. Xu Hao: Report of Fishery Equipment and Engineering Research in China (2005-2006). $J$. Fishery Modernization. (2007), 4, p.1-8.

[5]. Liu Ping, Xu Zhiqiang, Jiao Er: Optimization design of seine transport-roller based on ANSYS WorkBench. J. Fishery Modernization. (2015), 4,p.48-51.

[6]. Zhu Jiangkang: Application of the new ocean bottom gillnet net winch. J. Marine Fishery. (1994), 6, p.254-256.

[7]. Li Guozhu : Mechanical design and theory.M. Science Pres, BeiJing, (2003), P. 543-544. 